\title{
UNA EXCEPCIÓN A LOS DERECHOS DE AUTOR PARA LA COMUNICACIÓN PÚBLICA DE OBRAS POR PEQUEÑAS Y MEDIANAS EMPRESAS
}

[An Exception to Copyright for Small and Medium Sized Enterprises to Publicly Reproduce Works]

\author{
Alberto J. Cerda Silva* \\ Universidad de Chile, Santiago, Chile
}

\begin{abstract}
RESUMEN
El derecho de autor garantiza a su titular la explotación monopólica de sus obras, salvo las excepciones legales. En Chile, los pequeños establecimientos comerciales que mantienen encendido un radiorreceptor o televisión carecen de una autorización legal y, por tanto, deben obtener autorización (y pagar) a los titulares de derechos autorales. Este artículo aboga por una acotada autorización legal a favor de pequeñas y medianas empresas que les
\end{abstract}

\begin{abstract}
Copyright guarantees its holder the monopolistic commercial use of her/ his rights, except for legal exceptions. In Chile, small businesses that keep the radio or television on lack legal authorization to do so; therefore, they must obtain the permit (and pay for it) from the copyright holders. This article stands for a limited legal authorization in favor of small and medium-sized enterprises allowing them
\end{abstract}

RECiBIDo el 15 de abril y ACEPTADo el 20 de mayo de 2013

* Profesor asistente de Derecho informático de la Facultad de Derecho de la Universidad de Chile. Correo postal: Facultad de Derecho, Universidad de Chile, Pío Nono con Bellavista, Providencia, Santiago, Chile. Correo electrónico: acerda@uchile. $\mathrm{cl} \mathrm{El} \mathrm{autor} \mathrm{desea} \mathrm{expresar} \mathrm{su} \mathrm{agradecimiento} \mathrm{a} \mathrm{Daniel} \mathrm{Álvarez,} \mathrm{coordinador} \mathrm{de} \mathrm{investi-}$ gación del Centro de Estudios en Derecho Informático de la Universidad de Chile, quien proveyó invaluables comentarios y menciones a la historia legislativa, de la cual el mismo fue partícipe. 
permita encender la radio o televisión en sus dependencias.

Palabras Clave

Derechos de autor - Pymes - Pequeña y mediana empresa. to turn on the radio or television in their premises.

KEYWORDS

Copyright - SMBs - Small and medium sized enterprises.

\section{AnteCedentes}

La ley sobre propiedad intelectual garantiza a los creadores de obras artísticas, literarias y científicas una serie de derechos exclusivos sobre sus obras ${ }^{1}$. Por un lado, los derechos morales resguardan la conexión entre el autor y su creación, garantizando el reconocimiento de la autoría y resguardando la integridad de su obra ${ }^{2}$. Por otro lado, los derechos patrimoniales confieren al titular de los derechos, ya sea el autor o un tercero, la explotación monopólica de la obra ${ }^{3}$. Este último comprende las facultades de publicar, reproducir, distribuir, modificar, y ejecutar públicamente la obra ${ }^{4}$.

Los derechos de propiedad intelectual están sujetos a restricciones, sin embargo. Así su duración no es perpetua, sino que, en el caso de Chile, se extiende por regla general por toda la vida del autor más setenta años 5 . Vencido dicho plazo, la obra ingresa al dominio público y quienquiera puede hacer uso de ella sin autorización ${ }^{6}$. Mientras dicho plazo está pendiente, la obra sólo puede ser usada si se dispone de autorización del titular de los derechos, ya sea obtenida de este mismo o de una sociedad colectiva de derechos ${ }^{7}$, o bien la propia ley ha autorizado el uso, a través de lo que son conocidas como excepciones o limitaciones a los derechos de autor ${ }^{8}$.

Las excepciones y limitaciones a los derechos de autor establecidas por ley facultan a hacer uso de las obras sin autorización del titular de los derechos sobre dichas obras ni pago al mismo. Es el derecho interno de cada país, por regla general, el competente para establecer las excepciones. Sin embargo,

${ }^{1}$ Ley $\mathrm{N}^{\circ} 17.336$ sobre Propiedad Intelectual, publicada en el Diario Oficial el 2 de octubre de 1970, modificada por la Ley $\mathrm{N}^{\circ} 20.435$, publicada en el Diario Oficial el 4 de mayo de 2010, artículo 1.

${ }^{2}$ Ley $\mathrm{N}^{\circ} 17.336$, artículos 1 y 14.

${ }^{3}$ Ley $\mathrm{N}^{\circ} 17.336$, artículos 1 y 17.

${ }^{4}$ Ley $\mathrm{N}^{\circ} 17.336$, artículo 18 .

${ }^{5}$ Ley $\mathrm{N}^{\circ} 17.336$, artículo 10 .

${ }^{6}$ Ley $\mathrm{N}^{\circ} 17.336$, artículo 11.

${ }^{7}$ Ley $\mathrm{N}^{\circ} 17.336$, artículos 21 y 91.

${ }^{8}$ Ley $\mathrm{N}^{\circ} 17.336$, artículos $71 \mathrm{~A}$ a $71 \mathrm{~S}$. 
dichas autorizaciones no pueden extenderse desmesuradamente. De ahí que se haya acordado internacionalmente ciertas restricciones a su concesión a través de la llamada regla de los tres pasos. De acuerdo a dicha regla, las excepciones deben circunscribirse a determinados casos especiales, que no atenten contra la explotación normal de la obra, ni causen un perjuicio injustificado a los intereses legítimos del titular de los derechos?.

En Chile, el derecho de autor carecía de un adecuado régimen de excepciones ${ }^{10}$. Hasta la reforma de 2010, todas y cada una de las modificaciones introducidas a la ley sobre derechos de autor ${ }^{11}$, que data de comienzos de los setenta, habían incrementado los derechos de los titulares ${ }^{12}$. La reciente reforma en cambio fue algo más comprehensiva ${ }^{13}$. Inicialmente, el propósito de la reforma fue adecuar la legislación interna a las exigencias del tratado de libre comercio suscrito con los Estados Unidos ${ }^{14}$, mediante la adopción de normas específicas relativas a la responsabilidad de los prestadores de servicio de Internet por las eventuales infracciones cometidas por sus usuarios, la introducción de mejoras procedimentales, y la agravación de la responsabilidad penal por infracciones. Sin embargo, al mismo tiempo, el gobierno incluyó

${ }^{9}$ Compárese el Convenio de Berna para la protección de las obras literarias y artísticas ("Revisión de París", Francia, 24 de julio de 1971), artículo 9 (que fija la regla de tres pasos en relación con la adopción de ciertas excepciones al derecho de reproducción, circunscribiendo los intereses legítimos al autor) y el Acuerdo sobre los aspectos de los derechos de propiedad intelectual relacionados con el comercio (ADPIC), 15 de abril de 1994, Acuerdo de Marrakech que establece la Organización Mundial de Comercio, Anexo 1C, 1869 U.N.T.S. 299, artículo 13 (que extiende la aplicación de la regla de los tres pasos a otros derechos patrimoniales de autor y refiriendo los intereses legítimos al titular de los derechos autorales).

${ }^{10}$ Cerda, Alberto, Derecho de autor, academia y bibliotecas, en Cerda, Alberto - Ruiz, Claudio, Internet, Copyright y Derecho (Santiago, ONG Derechos Digitales, 2010), pp. 103-104.

${ }^{11}$ En general, véase: Herrera, Dina, Propiedad intelectual derechos de autor: Ley $N^{o}$ 17.336 y sus modificaciones (2a edición, Santiago, Editorial Jurídica de Chile, 1999).

${ }^{12}$ RuIz, Claudio, Hacia una dogmática para el acceso en Chile, en CERDA, Alberto (editor), Acceso a la cultura y derechos de autor (Santiago, ONG Derechos Digitales, 2008), pp. 31-53.

${ }^{13}$ Álvarez, Daniel, En busca de equilibrios regulatorios: Chile y las recientes reformas al derecho de autor, en Documento de Politica, 12 (Ginebra, Centro para el Comercio y el Desarrollo Sostenible, 2011); y Schuster, Santiago - Mahú, Jorge, Chile, en Hilty, Reto - NÉrisson, Sylvie (editores), Balancing Copyright: A Survey of National Approaches (Heidelberg, Springer, 2012), pp. 233-254.

${ }^{14}$ Tratado de Libre Comercio entre Chile y Estados Unidos, firmado el 6 de junio de 2003, publicado en el Diario Oficial el 30 de diciembre de 2003. 
un moderno régimen de excepciones y limitaciones al derecho de autor, así como ciertas normas que fortalecen el dominio público ${ }^{15}$.

En dicho contexto, la Confederación del Comercio Detallista y Turismo de Chile instó al legislador a adoptar una excepción específica para ciertos pequeños y medianos establecimientos empresariales, en relación con la comunicación al público que estos hacen de obras musicales ${ }^{16}$. En efecto, aún reconociendo los legítimos derechos de los autores, la Confederación llamaba al legislador a exceptuar del pago de derechos autorales a ciertas pequeñas y medianas empresas (PYMES) cuyo rubro operacional no fuese la música, limitando el cobro a aquéllos que requieren de ésta como componente principal para su funcionamiento. Asimismo, la Confederación llamaba la atención sobre ciertas prácticas de cobro que estimaba excesivas e instaba por la nulidad de los cobros judiciales emprendidos por la Sociedad Chilena del Derecho de Autor (SCD), la principal entidad de gestión colectiva de derechos de autor sobre obras musicales en el país.

En las siguientes páginas revisaremos hasta que punto la reforma acogió la inclusión de excepciones específicamente previstas para el funcionamiento de establecimientos comerciales constitutivos de pequeñas y mediana empresas, así como los efectos legales de la decisión legislativa al respecto.

\section{EXCEPCIONES PARA LA PEQUEÑA Y MEDIANA EMPRESA EN LA LEY $N^{\circ} 17.336$}

La Ley $\mathrm{N}^{\circ} 20.435$ introdujo un nuevo título tercero en la Ley $\mathrm{N}^{\circ} 17.336$ que contempla un catálogo de excepciones y limitaciones a los derechos autorales. Este régimen contribuye a paliar una sensible omisión de nuestro legislador, proveyendo certidumbre jurídica a la labor cotidiana de bibliotecas, museos y archivos, establecimientos educacionales, docentes e investigadores. Hasta antes de la entrada en vigor de la reforma, dichas instituciones y personas desarrollaban sus tareas fuera de la ley. Este era el caso de la Biblioteca Central para Ciegos que alberga una colección de

15 "Mensaje de S.E. la Presidenta de la República con el que inicia un proyecto de ley que modifica la ley $\mathrm{N}^{\circ} 17.336$, sobre propiedad intelectual” (Boletin $\mathrm{N}^{\circ}$ 5012-03), en Biblioteca del Congreso Nacional de Chile, Historia de la Ley No 20.435 Modifica la Ley $N^{\circ} 17.336$ sobre Propiedad Intelectual (2010), p. 8.

${ }^{16}$ Intervención de Rafael Cumsille, presidente de la Confederación del Comercio Detallista y Turismo de Chile, en "Informe de las Comisiones Unidas de Economía, Fomento y Desarrollo y de Cultura y de las Artes de la Cámara de Diputados recaído en el proyecto que modifica la Ley $\mathrm{N}^{\circ} 17.336$, sobre propiedad intelectual”, en Historia de la Ley $N^{o} 20.435$, cit. (n. 15), pp. 155-156. 
obras en formato accesible para personas con discapacidad visual ${ }^{17}$. Otras instituciones habían simplemente desistido de llevar adelante proyectos que pudiesen infringir derechos autorales. Este fue el caso de la edición de un texto y documental sobre política y artes visuales desarrollado por académicos de la Universidad de Chile y la Universidad ARCIS ${ }^{18}$. La reforma introdujo flexibilidades necesarias para permitir el desarrollo de iniciativas como éstas y otras análogas.

La mayor parte de las excepciones previstas en la ley, sin embargo, parecen excluir su aplicación por establecimientos de naturaleza comercial. Así, por ejemplo, se permite el uso de una obra para facilitar su acceso por personas con discapacidad, siempre que se efectúe "sin fines comerciales"19; una serie de excepciones permiten el desarrollo de actividades de bibliotecas y museos que no tengan "fines lucrativos" 20 ; se autoriza la comunicación de obras por determinados establecimientos educacionales, de beneficencia, bibliotecas, archivos y museos, siempre que la utilización se efectúe "sin fines lucrativos"21; y, se permite el empleo de obras para la elaboración de textos de estudio "sin ánimo de lucro"22. Será la jurisprudencia la que deberá desentrañar si algún distingo significativo existe en el aleatorio uso de las expresiones sin fines comerciales, sin fines lucrativos, y sin ánimo de lucro ${ }^{23}$. Una interpretación liberal sugeriría que el afán es excluir la explotación comercial encubierta

${ }^{17}$ Intervención de Jorge Opazo, presidente de la Biblioteca Central para Ciegos, en "Informe de las Comisiones Unidas de Economía, Fomento y Desarrollo y de Cultura y de las Artes de la Cámara de Diputados recaído en el proyecto que modifica la Ley $\mathrm{N}^{\circ} 17.336$, sobre propiedad Intelectual”, en Historia de la Ley $N^{\circ} 20.435$, cit. (n. 15), pp. 112-113.

${ }^{18}$ Véase: "Mesa Redonda con Pablo Oyarzún (moderador), Oscar Acuña, Alberto Cerda, Nury González, y Santiago Schuster”, Resignificación del patrimonio y autoria, en VII Seminario Patrimonio Cultural: Territorios en Conflicto ¿Por qué y para qué hacer memoria? (Santiago, DIBAM, 2005), pp. 66-91.

${ }^{19}$ Ley $\mathrm{N}^{\circ} 17.336$, artículo $71 \mathrm{C}$.

${ }^{20}$ Ley $\mathrm{N}^{\circ} 17.336$, artículos 71 I a $71 \mathrm{~L}$.

${ }^{21}$ Ley $\mathrm{N}^{\circ} 17.336$, artículo $71 \mathrm{~N}$. Nótese que la jurisprudencia ha insistido que la naturaleza del uso en cuestión y no de la entidad es la determinante para el uso de esta excepción. Así, pese a constituir una persona jurídica sin fines de lucro, el "Club de Jazz de Santiago" fue condenado a pagar por el uso de obras en actividades lucrativas, en el caso explotando un local público. Corte de Apelaciones de Santiago, "SCD vs. Club de Jazz de Santiago”, 4772-02, 21 de marzo de 2007, considerando $5^{\circ}$.

${ }^{22}$ Ley $\mathrm{N}^{\circ} 17.336$, artículo $71 \mathrm{M}$.

${ }^{23}$ Véase: CERDA, Alberto, Proyecto de ley corta sobre piratería: Modifica la Ley 17.336 sobre propiedad intelectual, en Revista Chilena de Derecho Informático, 4 (2004), pp. 196-197; y Puente Alba, Luz María, El ánimo de lucro y el perjuicio como elementos necesarios de los delitos contra la propiedad intelectual, en Revista Penal, 21 (2008), pp. 103-112. 
de las obras, pero no obstar a su empleo cuando ellas no son causa de enriquecimiento. Una interpretación conservadora intentará una lectura más restrictiva, impidiendo, por ejemplo, el uso de las excepciones por entidades de naturaleza comercial incluso para el desarrollo de actividades que no generan ingreso monetario alguno, así como el uso por entidades sin fines de lucro cuando medie algún interés monetario en ello. Una interpretación conservadora privaría a este grupo de excepciones de su potencial empleo por las PYMES.

La ley prevé varias excepciones susceptibles de ser empleadas por determinadas PYMES. Las empresas del rubro editorial, por ejemplo, pueden beneficiarse de una excepción para la cita de obras preexistentes ${ }^{24}$, y de otra para ciertas reproducciones de obras arquitectónicas y obras plásticas emplazadas en lugares públicos ${ }^{25}$. Las empresas de desarrollo de software, por su parte, disponen de nuevas excepciones que permiten la ingeniería inversa de programas de ordenador ${ }^{26}$. Sin embargo, estas excepciones no están exclusivamente concebidas para las PYMES, sino que favorecen a un amplio espectro de usuarios, pues prescinden del carácter comercial o no del uso que se hace de las obras, lo cual permite su empleo en actividades de naturaleza empresarial. Por otro lado, estas excepciones no refieren al objeto de nuestra indagación, cual es la difusión de obras musicales por las PYMES, particularmente cuando éstas encienden un radiorreceptor o televisión en sus dependencias.

La ley contempla dos excepciones específicas para el uso de obras por establecimientos comerciales. La primera de ellas permite a quienes venden equipos o programas computacionales el uso de obras con el exclusivo objeto de efectuar demostraciones a la clientela ${ }^{27}$. La segunda faculta a utilizar obras o fonogramas a quienes exponen y venden instrumentos musicales, aparatos de radio o televisión o cualquier equipo que permita la emisión de sonidos o imágenes ${ }^{28}$. Estos usos no requieren autorización del titular de los derechos ni pago al mismo. Sin embargo, están afectos a que la utilización de las obras tenga el exclusivo objeto de efectuar demostraciones a la clientela, que la emisión se realice dentro del propio local o de la sección del establecimiento destinada a este objeto, y que se verifique en condiciones que eviten su difusión al exterior ${ }^{29}$.

La excepción de emisión de obras en establecimientos comerciales tiene

\footnotetext{
${ }^{24}$ Ley $\mathrm{N}^{\circ} 17.336$, artículo $71 \mathrm{~B}$.

${ }^{25}$ Ley $^{\circ} 17.336$, artículo $71 \mathrm{~F}$.

${ }^{26}$ Ley $\mathrm{N}^{\circ} 17.336$, artículo $71 \mathrm{~N}$.

${ }^{27}$ Ley $\mathrm{N}^{\circ} 17.336$, artículo $71 \mathrm{E}$ inciso 2.

${ }^{28}$ Ley $\mathrm{N}^{\circ} 17.336$, artículo $71 \mathrm{E}$ inciso 1.

${ }^{29}$ Ley $\mathrm{N}^{\circ} 17.336$, artículo $71 \mathrm{E}$ inciso 1.
} 
un carácter bastante limitado. Ella permite demostraciones a la clientela, pero no operaría cuando equipos de televisión y radio se mantienen encendidos más allá de tal propósito, incluso si ello tiene lugar al interior del establecimiento en cuestión ${ }^{30}$. Notoriamente, a diferencia del texto previo de la ley ${ }^{31}$, la excepción en análisis no favorece a establecimientos que comercializan las obras, tales como un local de venta de música o video, sino que sólo a aquellos que venden equipamiento que permite la emisión de las obras. No existe explicación en la historia de la ley en torno la exclusión de tales establecimientos ${ }^{32}$, pero, dado que la emisión de las obras en ellos gira en el propio beneficio de los autores, parecería razonable restablecer la excepción también para quienes comercializan las obras mismas. Finalmente, para efectos de nuestro análisis, cabe hacer presente que está excepción, además de sumamente acotada, no es de exclusivo uso de las PYMES, sino que potencialmente de toda empresa que comercializa equipamiento computacional y audiovisual.

¿Permitirá alguna de las excepciones mencionadas la comunicación al público de obras musicales en establecimientos comerciales PYMES, manteniendo encendido un aparato radiorreceptor o de televisión continuamente? Hoy la música está presente en prácticamente todos los ambientes. Desde el sistema de transporte público hasta los servicios públicos cuentan con algún grado de musicalización. Lo mismo es válido para la antesala de consultas médicas y hospitalarias; los ascensores de edificios de oficinas; las zapaterías capitalinas, los almacenes de barrio, y hasta el servicio de taxis colectivos. ¿Deben todo este tipo de establecimientos requerir autorización y pagar para difundir música en ellos?

Como se ha mencionado previamente, a diferencia del régimen de common law, en nuestro sistema jurídico las excepciones son establecidas por el legislador, quien debe cumplir con la antes referida regla de los tres pasos. No cabe al juez crear nuevas excepciones, aunque si explorar la interpretación de las existentes. En este sentido, la reforma derogó la perniciosa doble-regla-de-los-tres-pasos ${ }^{33}$, que sujetaba a las excepciones reconocidas por ley a interpretación judicial a efectos de circunscribir aún más su uso.

${ }^{30}$ Corte de Apelaciones de La Serena, "SCD vs. Soc. Com. Iduya y Cía. Ltda.", 319 2007, 22 de junio de 2007 (que desecha la alegación de la demandada, Homecenter Real, de que la ejecución de las obras tuviese lugar sólo a efectos de la venta de equipos a un cliente).

${ }^{31}$ Ley $\mathrm{N}^{\circ} 17.336$, artículo 42, hasta antes de su modificación en 2010, disponía que "en los establecimientos comerciales en que se expongan y vendan [...] discos o cintas magnetofónicas, podrán utilizarse fonogramas o partituras libremente y sin pago de remuneración" bajo determinadas condiciones.

${ }^{32}$ Véase: Historia de la Ley $N^{o} 20.435$, cit. (n. 15).

${ }^{33}$ Véase: Álvarez, Daniel, cit. (n. 13), pp. 7-8. 
Así se impide que se cuestione judicialmente la eficacia de las excepciones previstas en la ley con el subterfugio de que ellas exceden la regla de los tres paso $^{34}$. Con todo, parece difícil extender la interpretación de cualquiera de las excepciones hoy previstas en Chile para permitir que establecimientos comerciales difundan obras a su clientela bajo la forma de musicalización de ambientes.

Peor aún, una interpretación favorable a establecimientos comerciales debe lidiar hoy con el riesgo de incurrir en responsabilidad penal. En efecto, nuestra ley sanciona el uso no autorizado de obras con penas pecuniarias y privativas de libertad, de hasta 540 días $^{35}$. Desafortunadamente, las disposiciones penales en cuestión son desproporcionadas por varias circunstancias. Si bien la ley fija la medida de la pena en atención al monto del daño, la ley no excluye de penas a las conductas infractoras de derechos autorales que no ocasionan perjuicios, ni siquiera aquellas infracciones cometidas sin ánimo de lucrar ${ }^{36}$. Esto es, todo uso no autorizado por el titular o por la ley, no sólo constituye una simple infracción civil, sino que además expone al usuario a responsabilidad penal. Así, un excesivo o inapropiado ejercicio de alguna de las excepciones previstas por la ley expone a su beneficiario a un serio riesgo, lo cual desincentiva asumir interpretaciones demasiado liberales del texto de la ley.

Sobre la base de lo hasta aquí dicho, para la difusión de música en establecimientos comerciales, sean o no PYMES, éstos requieren disponer de autorización de los titulares de derechos, ya sea la concedan directamente, o

${ }^{34}$ Véase: "Mesa Redonda con Mario Sol Muntañola (moderador), Juan José Marín, José Carlos Erdozaín, y Agustín González”, El Test de las Tres Etapas y la Comunicación Pública, en Copyright y Derecho de Autor: ¿Convergencia Internacional en un Mundo Digital? en Revista de Internet, Derecho y Politica de la Universitat Oberta de Catalunya, 1 (2005), pp. 21-34 (donde se examina una regla similar existente en el derecho español); y Schuster, Santiago - Mahú, Jorge, cit. (n. 13), p. 239.

${ }^{35}$ Ley $\mathrm{N}^{\circ} 17.336$, artículo 79.

${ }^{36}$ En Derecho comparado es usual que se prevean ciertas limitaciones a la criminalización de la infracción a los derechos de autor, mediante la des-criminalización de las infracciones de minimis y los ilícitos cometidos sin fines de lucro; la adopción de un nutrido set de excepciones que actúan como circunstancias eximentes de responsabilidad penal; la exigencia de elementos subjetivos en los tipos penales; y, el reconocimiento de ciertas circunstancias legales absolutorias. Ninguna de dichas limitaciones de responsabilidad penal existen en la normativa nacional, salvo las recientes excepciones previstas en la ley. Lo propio sucede en derecho internacional, en el cual se exige sanciones penales consistentes en prisión o multas en casos de "wilful copyright piracy on a commercial scale". Véanse el Acuerdo sobre los Aspectos de los Derechos de Propiedad Intelectual relacionados con el Comercio (ADPIC), de 15 de abril de 1994; y el Acuerdo de Marrakech que establece la Organización Mundial de Comercio, Anexo 1C, 1869 U.N.T.S. 299, artículo 61. 
bien a través de la entidad de gestión colectiva de que éstos sean miembros. La siguiente sección revisa alguna jurisprudencia de los tribunales nacionales en relación con el cobro de derechos por la comunicación pública de obras musicales en establecimientos comerciales, con el propósito de graficar ciertos excesos cometidos al respecto y, posteriormente, argumentar por una solución al tema, mediante la adopción de una excepción específica a los derechos de autor en favor de las PYMES, en orden a permitir que éstas mantengan encendido aparatos de radio o televisión en sus dependencias.

\section{COMUNICACIÓN DE OBRAS MUSICALES EN PEQUEÑAS Y} MEDIANAS EMPRESAS

La mayor parte de la jurisprudencia de los tribunales de justicia en torno a la ley sobre propiedad intelectual se refiere a acciones de cobro intentadas por la Sociedad Chilena del Derecho de Autor (SCD), la principal entidad nacional de gestión colectiva de derechos sobre obras musicales, por la difusión de obras de sus miembros en contra de establecimientos comerciales de la más variada naturaleza. La SCD otorga licencias generales para el uso de obras de su repertorio y, naturalmente, hace exigible dichos derechos en relación con quienes no obtienen dicha autorización ni pagan la tarifa correspondiente. Por su parte, la Confederación del Comercio Detallista y Turismo de Chile, la principal agrupación gremial de PYMES, ha rechazado algunas acciones de cobro emprendidas por SCD por estimarlas abusivas ${ }^{37}$. Los tribunales desafortunadamente han resuelto dichas diferencias no siempre con acierto ni consistencia, según veremos.

El titular de los derechos de autor tiene el derecho exclusivo de controlar la comunicación pública de su obra. Para mayor precisión, el legislador ha creído conveniente definir comunicación pública como todo acto que permite difundir una obra dando acceso a ella a una pluralidad de personas, reunidas o no en un mismo lugar, sin que medie distribución de ejemplares. ${ }^{38}$ Constituye también tal comunicación la puesta a disposición de la obra al público, de forma tal que los miembros del público puedan acceder a ella desde el lugar y en el momento que cada uno de ellos elija ${ }^{39}$, esto es, cuando una obra se hace disponible al público en línea, por ejemplo, a través de Internet. Dejemos de lado la puesta a disposición en línea y concentrémonos en la primera modalidad de comunicación al público definida por la ley, que es el objeto de atención del presente artículo.

${ }^{37}$ Véase "Intervención de Rafael Cumsille”, en Historia de la Ley No 20.435, cit. (n. 15), pp. 155-156.

${ }^{38}$ Ley $\mathrm{N}^{\circ} 17.336$, artículo $\left.4 \mathrm{v}\right)$.

${ }^{39}$ Ley $\mathrm{N}^{\circ} 17.336$, artículo $4 \mathrm{v}$ ). 
En cuanto a quién es obligado a la obtención de autorización y pago de tarifas, el artículo 21 de la ley ha previsto que quien tiene la explotación de un recinto o medio de comunicación podrá obtener la autorización necesaria de las entidades de gestión colectiva de derechos y deberá pagar a las mismas ${ }^{40}$, sin perjuicio de la autorización individual del autor para utilizaciones singulares de sus obras. Así, en el caso del recinto conocido como "CasaPiedra", que arrienda espacio físico para eventos en los cuales previsiblemente se emplea música protegida por derechos de autor, la empresa administradora del recinto ha sido obligada al pago ${ }^{41}$, aun cuando se excusaba de ello en el contrato suscrito con sus arrendatarios esporádicos ${ }^{42}$. La disposición recién mencionada parece establecer una responsabilidad conjunta del propietario, concesionario, usuario, empresario, arrendatario o de quien explote el recinto, a efectos de garantizar el efectivo resguardo de los derechos de autor. Pero es bastante dudoso que el legislador haya intentado requerir de cada uno de ellos la obtención de una autorización y un pago de tarifas adicionales; al contrario, lo razonable es presuponer que el pago efectuado por uno de ellos beneficia a los restantes respecto del uso en cuestión.

El primer inconveniente que ha debido sortear la jurisprudencia, relacionado con quien está obligado al pago, es determinar si el concepto comunicación pública incluye la retransmisión final de la comunicación efectuada por un tercero, tal como un servicio de música ambiental o una simple radioemisora. En términos concretos, ¿debe un restaurante, fuente de soda, o zapatería pagar derechos para mantener encendido un radiorreceptor para disfrute de sus propios dependientes y eventualmente de su clientela? La respuesta tiene complicaciones adicionales cuando se discute el carácter

${ }^{40}$ Ley $\mathrm{N}^{\circ} 17.336$, artículo 21 inciso $2^{\circ}$, dispone: "todo propietario, concesionario, usuario, empresario, arrendatario o persona que tenga en explotación cualquier sala de espectáculos, local público o estación radiodifusora o de televisión en que se representen o ejecuten obras teatrales, cinematográficas o piezas musicales, ofonogramas o videogramas que contengan tales obras, de autores nacionales o extranjeros, podrá obtener la autorización de que tratan los articulos anteriores a través de la entidad de gestión colectiva correspondiente, mediante una licencia no exclusiva; y estará obligado al pago de la remuneración que en ella se determine, de acuerdo con las normas del titulo $V$ ".

${ }^{41}$ Corte Suprema, "SCD vs. Cheffco S.A.", 718-2009, 27 de enero de 2011, sentencia de casación, considerando $9^{\circ}$. En contra, véase el voto disidente del mismo fallo, en que se argumenta que la sociedad administradora del recinto CasaPiedra no estaba obligada al pago de derechos porque la conducta gravada en el artículo 21 de la Ley $\mathrm{N}^{\circ}$ 17.336 es la de quien lucra con el uso del repertorio musical, no la de quien lo hace con el arriendo de inmuebles.

${ }^{42}$ Ibíd., considerando $11^{\circ}$, que reconoce la inoponibilidad de la cláusula contractual suscrita entre CasaPiedra y sus arrendatarios en relación con los derechos representados por la entidad de gestión colectiva de derechos autorales. 
público de dicha comunicación en un recinto privado. ¿Debe pagar un hotel por poner a disposición de sus pasajeros un equipo de televisión en sus habitaciones?

El 2001, el Mercado La Recova de La Serena fue condenado a pagar derechos autorales a la SCD, a pesar de que la comunicación efectuada por la administración de dicho establecimiento se hacia en virtud de un contrato de servicios de musicalización provisto por un tercero, la empresa Scamusica ${ }^{43}$. Según la corte, la retransmisión en un espacio público como el mercado requería de una licencia independiente a aquélla concedida a la empresa que provee el servicio de música ambiental. Años después, en el caso del autoservicio de carretera "Am-Pm", la Corte Suprema rechazó una demanda bajo análogas circunstancias, pues la autorización concedida por la SCD a Scamusica "necesariamente inclu[ye] la utilización de las obras musicales protegidas que lleven a cabo los abonados", siendo improcedente requerir una segunda autorización y pago de tarifa de éstos ${ }^{44}$.

La jurisprudencia sentada por la Corte Suprema en "Am-Pm" subentiende que, en el caso de los servicios de musicalización ambiental de pago, es la empresa prestadora de servicios la responsable de obtener autorización y pagar derechos autorales para la difusión de las obras en recintos de terceros. No son éstos los llamados a efectuar un nuevo pago y requerir una nueva autorización. Esto es particularmente cierto, cuando en la especie, dicha empresa estaba autorizada por la SCD para ofertar servicios de musicalización. Una decisión como la relativa al caso de La Recoba, al contrario, estatuye un indebido doble pago.

La Corte Suprema ha rechazado otros casos en que se plantea la comunicación al público a través de la simple transmisión de una obra puesta a disposición por un tercero. En el caso seguido en contra de la conocida tienda de arrendamiento de películas "Blockbuster", el máximo tribunal rechazó que la demandada debiese pagar derechos autorales por la exhibición de los "trailers" de películas, cuyas bandas sonoras incluían obras del repertorio de la entidad de gestión colectiva. La decisión explícitamente repudió un doble pago, pues "no proced [e] un nuevo pago por tales derechos puesto que dicha remuneración, como se estableció, correspondió en su oportunidad al

${ }^{43}$ Corte de Apelaciones de La Serena, "SCD vs. Sociedad Agrocomercial Limitada", 24513-2000, 12 de septiembre de 2001: acoge demanda de pago de derechos autorales por la trasmisión de obras musicales en el Mercado de la Recova de La Serena a través de servicios provistos por Scamusica.

${ }^{44}$ Corte Suprema, “SCD vs. Soc. Com. Jeria y Cía Ltda.”, 4898-2008, 29 de octubre de 2010, sentencia de reemplazo, considerando $3^{\circ}$ : rechaza demanda de pago de derechos autorales por la transmisión de obras musicales en el Autoservicio Am-Pm, ubicado en la Panamericana Sur, provistos a través de Scamusica. 
creador de la obra que contiene la banda sonora"45. Habiendo los productores cinematográficos cumplido con obtener autorización y pagar por derechos autorales sobre la música incorporada en sus películas, es improcedente obtener otro pago de quien exhibe públicamente trailers publicitarios de dichas películas.

El razonamiento de la Corte Suprema bien podría trasladarse a otros casos en que determinados establecimientos no hacen sino transmitir obras que son puestas a su disposición por servicios provistos por terceros, tales como empresas de cable, canales de televisión, y radioemisoras. Estas empresas presumiblemente disponen de la adecuada autorización de la entidad de gestión colectiva de derechos para comunicar obras de su repertorio, incluso si la recepción y decodificación de su señal se verifica más allá del living de nuestro hogar. De este modo, por ejemplo, un boliche o chiringuito que simplemente mantiene encendido el radiorreceptor no debía ser forzado a efectuar un pago ni a la obtención de una autorización adicionales. Desafortunadamente, no existe una línea jurisprudencial consistente al respecto, como veremos.

En diversas ocasiones los tribunales de justicia han impuesto la obligación de obtener autorización y pagar derechos de autor a pequeños establecimientos comerciales que mantienen encendidos sus radiorreceptores o televisores. Así, por ejemplo, en el caso de un establecimiento de comidas ${ }^{46}$, un restau-

${ }^{45}$ Corte Suprema, "SCD vs. Blockbuster Video Internacional Corporation Chile Ltda.", 2764-2010, 30 de septiembre de 2010, considerando $4^{\circ}$.

${ }^{46}$ Corte Suprema, "SCD vs. Jesús Sanhueza Acuña", 7378-2008, 28 de julio de 2010, considerando $3^{\circ}$ : rechaza el recurso pues "en el negocio de comidas de la demandada se difundian obras musicales protegidas mediante un radio receptor conectado a parlantes". 
rante ${ }^{47}$, una fuente de soda ${ }^{48}$, un café ${ }^{49}$, un local de venta de empanadas ${ }^{50}$, una panadería $^{51}$, etcétera ${ }^{52}$. En todos estos casos, los establecimientos demandados sintonizaban la radio o televisión dentro de su recinto, haciéndose responsables de la comunicación al público de las obras musicales, aún si la entidad de gestión colectiva de derechos había autorizado ya a las radioemisoras o canales de televisión sintonizados.

Mención aparte merece el caso de los establecimientos hoteleros. En general, el hecho de disponer simplemente de equipamiento musical y televisivo para uso de sus huéspedes en las habitaciones ha sido suficiente para atraer la censura judicial y ser condenados al pago de derechos autorales, rechazando el argumento de que la comunicación en cuestión no es pública dada la privacidad de las habitaciones ${ }^{53}$. En otro caso análogo, la Corte Suprema rechazó

${ }^{47}$ Corte de Apelaciones de Arica, “SCD vs. Aurelia Alcón”, 14- 2007, 30 de mayo de 2007: acoge la demanda contra la dueña del Restaurante Yuri de Arica, por difundir obras musicales en su establecimiento a partir de las transmisiones de televisión por cable. Véase también Corte de Apelaciones de La Serena, "SCD vs. Feng Ermei", 811 2008, 21 de enero de 2009 (contra restaurante de comida china Sheng Chang).

${ }^{48}$ Corte de Apelaciones de Rancagua, "SCD vs. Juan Carlos Valenzuela Letelier", 22396-2004, 7 de noviembre de 2005: acoge demanda contra Fuente de Soda La Boca Loca, en la ciudad de San Fernando, por usar y difundir al público obras musicales de diversos autores del repertorio administrado por la demandante, mediante el empleo de un receptor de radio y otro de televisión.

${ }^{49}$ Corte de Apelaciones de Concepción, "SCD vs. Sociedad Rubio y Ramos Ltda.", 888-2004, 27 de julio de 2004: acoge la demanda en contra del Café Silvestre, ya que la ejecución de obras mediante el empleo de un receptor de radio y la colocación de altoparlantes a fin de difundir música ambiental es una "comunicación pública propia $e$ independiente de la comunicación que efectúa el primer trasmisor, en el caso, la radioemisora".

${ }^{50}$ Corte Suprema, “SCD vs. Roberto Figueroa Quezada”, 7179-2008, 22 de julio de 2010: acoge la demanda en contra del local de ventas de Empanadas de Emeterio II, en el cual se difunden al público obras musicales contemporáneas.

${ }^{51}$ Corte Suprema, “SCD vs. Soc. Com. e Ind.”, 2374-2009, 28 de marzo de 2011 : acoge la demanda contra Panadería Pancal por disponer al interior de su establecimiento de dos parlantes y un altavoz a través de los cuales se escuchan radioemisoras locales.

${ }^{52}$ Véanse, por ejemplo: Corte Suprema, "SCD vs. Supermercado Algarrobo Ltda.", 2077-2008, 28 de septiembre de 2009: acoge la demanda por la ejecución de obras a través de parlantes de un restaurante; Corte de Apelaciones de Santiago, "SCD vs. He Zhi Da y otros", 2211-2009, 28 de enero de 2010: acoge la demanda en contra de un pequeño local de comida china capitalino, por la utilización masiva y comunicación al público con altavoces o parlantes de obras musicales de creadores nacionales y extranjeros, sin autorización.

${ }^{53}$ Corte de Apelaciones de La Serena, "SCD vs. Hotel La Herradura”, 91-2007, 22 de junio de 2007 , considerandos $2^{\circ}$ y $4^{\circ}$ : se condena al demandado porque en " $e l$ establecimiento del demandado se escucha, en las diferentes habitaciones música, la que 
la alegación de un establecimiento hotelero que disponía de televisión por cable en las habitaciones, porque el hotel constituye una unidad indivisible de dependencias al servicio del público en general, con prescindencia de las formas en que se utilicen ${ }^{54}$.

Algún fallo ha, en cambio, rechazado las acciones de cobro de derechos autorales emprendidos en contra de este tipo de establecimientos, cuando ellos se limitan a encender un radiorreceptor. En el caso del "Café Vizzio", la corte rechazó la demanda porque "extender -en la práctica- la carga legal del pago del derecho hasta el momento en que se enciende un aparato de radio, resulta injustificado y carente de basamento jurídico" "Es. Este caso sugiere, como la Corte Suprema en el caso "AM-Pm", que es improcedente requerir una segunda autorización y pago de tarifa por simplemente sintonizar una radio o canal de televisión.

En el caso del "Café Vizzio", la corte incorporó otro argumento para rechazar la demanda: el establecimiento demandado no es de aquéllos en que "se encuentra incorporada la emisión de piezas musicales para el entretenimiento del público"s6. El fallo introduce un criterio para diferenciar entre los establecimientos que estarían obligados a un pago y aquéllos que no: el grado de conexión entre la emisión musical y el entretenimiento brindado

es difundida por medio de televisores", y rechaza el carácter privado de la comunicación, pues ella se "utiliza para promover el giro del negocio, y con un claro afán de lucro". Véase también Corte Suprema, "SCD vs. Sociedad Hotelera Celedón Limitada", 6.3892008, 7 de abril de 2009: rechaza el recurso intentado por la demandada contra el fallo que le condenó a pagar derechos de autor por la utilización de obras musicales comunicadas al público mediante receptor de televisión; y, Corte de Apelaciones de Puerto Montt, "SCD vs. Karjukar S.A.", 372-2009, 27 de noviembre de 2009: condena a la demandada por comunicar obras musicales del repertorio de la demandada, a través de receptores de radio y televisión, además de parlantes, ubicados en habitaciones del Hotel Le Mirage.

${ }^{54}$ Corte Suprema, "SCD vs. Sociedad Hotelera Valle Del Encanto Limitada", 862006, 26 de marzo de 2007, considerandos 14 y 16. Véase también, Corte de Apelaciones de La Serena, "SCD vs. Pedro Campos Correa", 909-2007, 11 de diciembre de 2007, considerando $9^{\circ}$ : condena a la demandada por mantener equipos de televisión a disposición de sus huéspedes en "Cabañas La Herradura" a través de los cuales se difunden obras empresas por los respectivos canales de televisión, sin que las licencias o autorizaciones concedidas a éstos puedan hacerse "extensivas a otro utilizador del mismo, porque se trata de dos actos distintos y separados de comunicación pública"; y, Corte de Apelaciones de La Serena, "SCD vs. Soc. de Inv. Geomovi de Elqui”, 339-2008, 25 de agosto de 2008: condena a la demandada por análogas circunstancias en "Cabañas Yunkay".

${ }^{55}$ Corte de Apelaciones de Iquique, “SCD vs. Soc. Com. Vasilma Ltda.”, 187-2004, 26 de abril de 2006 , consideranndo $8^{\circ}$.

${ }^{56}$ Ibíd. 
al público. Así, prosigue el fallo en cuestión, estarían obligados "un local nocturno, discotheque (sic), un pub (sic), un restaurante o algún otro semejante que utilice para su giro la música", mientras un café no lo estaría ${ }^{57}$. El criterio judicial, que carece de sustento en el texto de la ley ${ }^{58}$, introduce un criterio de razonabilidad: aquellos establecimientos en que la música forma parte esencial del giro del negocio deben estar obligados a la obtención de autorización y pago de tarifas por derechos autorales; en cambio, aquéllos en que tal uso no es esencial deben quedar excluidos de tales obligaciones.

La generalidad de la jurisprudencia nacional parte del amplio concepto de comunicación pública y constata que las disposiciones de la ley sobre derechos de autor no incluyen una excepción que permita a pequeños y medianos establecimientos comerciales encender sus radiorreceptores ni televisores sin que medie autorización del titular de los derechos de autor o la entidad de gestión colectiva de derecho que le represente. Tras ello, se obliga a dichos establecimientos a requerir autorización y pagar tarifado, incluso si las radioemisoras y canales de televisión han obtenido tal autorización y pagado por ello. Este criterio jurisprudencial resulta excesivo e instituye un injusto doble pago.

El criterio jurisprudencial que, sobre la base de comunicación pública, requiere a los establecimientos comerciales requerir autorización y soportar un nuevo pago es excesivo. Conceptualmente, este criterio debía requerir el pago de derechos autorales al taxista que mantiene su radio encendida, a quien canta canciones de amor a su enamorada por teléfono (especialmente si ésta pone la llamada en modalidad speaker), o a quien inspirado en los ochenta circula por las calles cargando a cuestas un radiorreceptor encendido. Con acierto, algún legislador reclamaba que la aplicación estricta de la norma resultaría aplicable a quien silba una melodía en la calle, así como fue aplicada "al dueño de un taller de bicicletas... que durante la realización de sus labores sintoniza una radio" "59. Cualquiera de dichas situaciones, aún siendo técnicamente una comunicación al público, está más allá de la protección que el legislador ha querido brindar a los creadores.

El criterio jurisprudencial es particularmente injusto cuando requiere un doble pago. Con acierto la jurisprudencia de minoría (en el caso del "Café Vizzio") y en casos análogos (como los casos de "Blockbuster" y "Am-Pm") han rechazado el pago por mera transmisión de obras, cuando los derechos han sido ya pagados por el tercero que provee servicios. Posiblemente es razo-

${ }^{57}$ Ibíd.

${ }^{58}$ Véase la Ley $\mathrm{N}^{\circ} 17.336$, artículo 21.

${ }^{59}$ Intervención del Senador Coloma, en Biblioteca del Congreso NaCioNAL DE CHILE, Historia de la Ley $N^{\circ} 20.416$ que fija normas especiales para las Empresas de Menor Tamaño (2010), pp. 702. 
nable requerir pago de aquellos establecimientos en que la difusión de obras es parte esencial de su giro, pero la jurisprudencia ha extendido el pago más allá y los cobros llegan a todo tipo de establecimientos. Una interpretación finalista de la regulación de derechos autorales debería rechazar dichos cobros por constitutivos de un enriquecimiento sin causa, una doctrina que goza de amplia aceptación en nuestra doctrina y jurisprudencia ${ }^{60}$. Los derechos autorales han sido pagados por los camales de televisión o estaciones de radio, no deben nuevamente ser pagados por quienes son mera audiencia.

Todavía más. La ausencia de una excepción a favor de pequeños y medianos establecimientos trae aparejados significativos costos para éstos, no sólo en licenciamiento, sino también en litigación. Entrampados sorpresivamente en litigación por lo que creen constituir un razonable uso, pequeños y medianos establecimientos asumen elevados costos transaccionales, no sólo por la especialización jurídica de la materia, sino también por el notorio desequilibrio procesal en que son puestos. La ley presume que las entidades de gestión colectiva representan a los titulares de derechos sobre obras de su repertorio ${ }^{61}$, pero la mayor parte de los tribunales otorga a dichas entidades dos presunciones más a su favor. Primero, las cortes han presumido que los derechos sobre las obras se encuentran vigentes, obligando a los establecimientos demandados a probar que no es así ${ }^{62}$. Segundo, la generalidad de las cortes presume que las obras difundidas son parte del repertorio de la entidad de gestión colectiva demandante, obligando a los demandados a probar lo

${ }^{60}$ Véase, e.g.: BARRIEntos, J., El pago de lo no debido en el Derecho chileno (Santiago, LexisNexis, 2003), pp. 19-22, donde cita la doctrina del enriquecimiento sin causa en conexión con el pago de lo no debido en la literatura nacional; DuCCI, Carlos, Derecho civil: Parte general (Santiago, Editorial Jurídica de Chile, 2007), pp. 32-33, donde se refiere al enriquecimiento sin causa como principio fundamental del Derecho con amplia base en la jurisprudencia y disposiciones del Código Civil; Alessandri, A. Somarriva, M. - Vodanovic, A., Tratado de las obligaciones (2a edición, Santiago, Editorial Jurídica, 2001), I, pp. 61-63.

${ }^{61}$ Ley $\mathrm{N}^{\circ} 17.336$, artículo 102.

${ }^{62}$ Esta presunción recibió consagración legal con la reforma del 2010. Véase Ley $\mathrm{N}^{\circ} 17.336$, artículo $85 \mathrm{H}$, en donde se presume que los derecho de autor y los derechos conexos subsisten sobre una obra o fonograma cuya fecha de su primera publicación sea inferior a setenta años. Con todo, aun en este caso es necesario probar el año de publicación de las obras ejecutadas. 
contrario $^{63}$. Muy excepcionalmente estos establecimientos han salido airosos de dichas desmesuradas presunciones ${ }^{64}$.

Aunque una interpretación judicial más mesurada podría paliar esta

${ }^{63}$ Véanse, e.g.: Corte Suprema, "SCD vs. Henríquez Correa", 5257-2008, 5 de abril de 2010 , considerando $5^{\circ}$ : resuelve que, acreditado que sea que la demandada opera un local nocturno donde se difunde música contemporánea, debe presumirse que las obras musicales que allí se utilicen están incorporadas al repertorio tutelado por la entidad de gestión colectiva, correspondiendo a la demandada probar que se trata de obras de dominio público; Corte Suprema, "SCD vs. Jesús Sanhueza Acuña”, 7378-2008, 28 de julio de 2010 , considerando $3^{\circ}$ : pone explícitamente la carga de la prueba en la demandada, en orden a demostrar que las obras musicales ejecutadas no son aquéllas representadas por la entidad de gestión colectiva; Corte Suprema, "SCD vs. Sociedad Torres y Cía. Ltda.", 31-2000, 15 de enero de 2001, considerando $4^{\circ}$ : resuelve que, acreditado que la demandada es una discoteca, corresponde a ella probar que las obras que comunica son de dominio público y no a la demandante, ya que "lo normal, corriente, u ordinario" será que la música bailable contemporánea ejecutada forme parte del repertorio de la entidad de gestión colectiva. Véase también Corte Suprema, "SCD vs. Roberto Figueroa Quezada", 7179-2008, 22 de julio de 2010, considerandos $5^{\circ} \mathrm{y}$ $6^{\circ}$. Todos los fallos tienen votos disidentes, que rechazan la presunción judicial por infringir el principio civil de que quien alega las obligaciones debe probar su existencia (artículo 1968 CC.) y el principio criminal que presume inocencia mientras no se acredite lo contrario (artículo 4 CPP.). Véase también Corte de Apelaciones de Arica, "SCD vs. Rosalía Villanueva García", 478/2010, 2 de marzo de 2011, considerando $3^{\circ}$ : "recae sobre la demandada el peso de la prueba, esto es, demostrar que en su establecimiento se difunden obras que no son de aquellas contempladas en el repertorio de la SCD".

${ }^{64}$ Véanse, e.g.: Corte de Apelaciones de Santiago, "SCD vs. Saho Ten Yu”, $3036-$ 2002, 18 de enero de 2007: desestima la demanda porque el acta de un ministro de fe "no específica las obras musicales difundidas que corresponden a los registros representados por la sociedad chilena del derecho de autor", y más notablemente Corte de Apelaciones de Antofagasta, "SCD vs. Soc. Lugaro y Lugaro Ltda.", 538-2009, $1^{\circ}$ de diciembre de 2009 , considerandos $5^{\circ}$ y $9^{\circ}$ : se revoca la decisión de primera instancia y rechazando la demanda intentada contra Gollun Discotheque porque "la personería con que cuenta la sociedad que demanda, no es de carácter general o universal, es decir, no incluye a la totalidad de los autores, compositores, artistas, intérpretes o ejecutantes existentes, sino exclusivamente a sus asociados y representados nacionales o extranjeros", por lo que ha debido acreditar a quiénes representa. Así la demanda es rechazada por "la falta de acreditación de la legitimación activa con que la sociedad demandante contaria para comparecer asumiendo la representación que se arroga, sino también por la manifiesta carencia de antecedentes sobre la individualización de las personas cuyos derechos aquella está habilitada para defender y la de los temas que han debido considerarse protegidos". Véase también, Corte de Apelaciones de Santiago, "SCD vs. Díaz Poblete y Cornejo Ltda.", $7397-$ 2009, 21 de septiembre de 2010, considerandos $2^{\circ}$ a $5^{\circ}$ : se rechaza la demanda contra la discoteca La Berenjena, porque: "para los efectos de poder acceder a cobrar derechos de autor la SCD, debe acreditar que en el establecimiento en cuestión se difunden obras que pertenecen al repertorio contenido en sus archivos", para lo cual no allegó pruebas suficientes, antes, al contrario, la demandada probó que "la música difundida en el local en cuestión 
problemática, nos parece que la solución definitiva de este inconveniente pasa por una modificación a la ley, dado que las decisiones judiciales tienen efectos relativos. Si bien el texto de la Ley parece no hacer distingo alguno y prácticamente todo establecimiento en el cual se ejecutan obras musicales estaría obligado a gestionar autorizaciones y pagar derechos, debía de existir una excepción a favor de aquellos pequeños y medianos establecimientos que se limitan a sintonizar una radioemisora o canal de televisión, cuando la comunicación de obras musicales no forma parte esencial del giro del negocio, pues en tal caso la autorización y el pago han sido ya efectuados por el emisor de la señal. A ésta habría que adicionar una modificación a la excepción en beneficio de los establecimientos que venden obras para la demostración de ellas mediante su ejecución. La siguiente sección delinea los aspectos centrales de una propuesta de tal naturaleza.

\section{UNA EXCEPCIÓN PARA LA COMUNICACIÓN PÚBLICA POR PEQUENAS Y MEDIANAS EMPRESAS}

Durante la discusión de la reforma a la Ley $\mathrm{N}^{\circ} 17.336$ no sólo se expresó el interés en incluir una excepción específica para que pequeños establecimientos comerciales pudiesen sintonizar radioemisoras y canales de televisión en sus dependencias, sino que hubo propuestas concretas. En el Senado fue introducida una indicación legislativa que específicamente disponía que "Cuando la utilización de fonogramas o reproducciones se realice por establecimientos comerciales pequeños o en recintos de espera de atención al público, no procederá el pago de retribución alguna" ${ }^{55}$. La indicación fue discutida en el Senado, donde suscitó fuerte controversia ${ }^{66}$. Algunos parlamentarios la desestimaron como carente de criterio jurídico y ambigua, mientras otros estimaron conveniente modificar su redacción para recepcionar la jurisprudencia de la Corte Suprema que había eximido a ciertos establecimientos del pago de derechos autorales por la mera retransmisión radial y televisiva de

corresponde a autores desconocidos o emergentes, cuyas composiciones no forman parte del repertorio de la SCD y que en ese local se hacen espectáculos en vivo y fiestas o eventos".

${ }^{65}$ Boletin No 5.012-03 "Indicaciones Formuladas durante la Discusión General del proyecto de Ley, en Segundo Trámite Constitucional, que Modifica la Ley No 17.336 sobre Propiedad Intelectual”, 7 de abril de 2008, en Historia de la Ley $N^{\circ} 20.435$, cit. (n. 15), p. 459.

${ }^{66}$ Véase el "Segundo Informe de las Comisiones de Economía y Educación, Cultura, Ciencia y Tecnología, Unidas del Senado, en segundo trámite constitucional, que Modifica la Ley $\mathrm{N}^{\circ} 17.336$, sobre Propiedad Intelectual”, en Historia de la Ley $N^{o}$ 20.435, cit. (n. 15), pp. 524-526. 
obras. Varios legisladores insistieron en su necesidad, aún si fuese necesario modificar sus términos.

En cambio, el Ejecutivo rechazó la propuesta de incluir una excepción como la analizada por varias razones ${ }^{67}$. En primer término, sostuvo que ella excedía el ámbito de la modificación del proyecto y que la idea ya había sido debatida precedentemente sin prosperar ${ }^{68}$. Enseguida, argumentó que la indicación era contraria a los acuerdos internacionales, particularmente al Convenio de Berna por infringir la ya mencionada regla de los tres pasos. Por último, el Ejecutivo rechazó que los autores soportasen en su patrimonio las facilidades a pequeñas y medianas empresas. Como resultado de la resistencia del Ejecutivo a la inclusión de tal excepción y para proseguir con la discusión de otras disposiciones, la propuesta de incluir una excepción a favor de pequeños establecimientos comerciales fue retirada por su proponente.

La discusión en torno a adoptar una excepción a favor de pequeños y medianos establecimientos comerciales no estaba agotada, sin embargo. De hecho, junto con la discusión de la reforma a la ley sobre derechos de autor, en el Congreso se tramitaba paralelamente la ley que fijaría normas especiales para las empresas de menor tamaño ${ }^{69}$. Esta ya había sido aprobada por la Cámara de Diputados, pero el Senado decidió incluir en ella una excepción, conforme a la cual no se entendería ejecución pública "la recepción de una señal de radioemisora o televisión abierta, en las oficinas, talleres o establecimientos de micro o pequeñas empresas, en caso que no produzca ingresos por ventas al titular de la empresa y no forme parte del giro o de los bienes o servicios dispuestos para su adquisición por los clientes" ${ }^{\text {. }}$. La modificación fue aprobada por la Cámara de Diputados ${ }^{71}$, y el proyecto de ley enviado a la Presidencia

${ }^{67}$ Ibíd.

${ }^{68}$ Se refiere al "Mensaje Presidencial 228-350 del 12 de enero de 2004 con que inicia un proyecto de ley modificatorio de la Ley 17.336 sobre Propiedad Intelectual", conocido como "Ley Corta de Piratería", el cual reforzaba las disposiciones sobre crímenes y delitos relativos a los derechos autorales, pero obviaba toda consideración a la inclusión de excepciones y limitaciones a los derechos de autor en la ley. La iniciativa, fuertemente cuestionadas por organizaciones gremiales y sociales, suscitó reparos de los legisladores, siendo finalmente abandonada su tramitación en el Congreso Nacional y luego retirada por el Ejecutivo. Véase Cerda, Alberto, Proyecto, cit. (n. 23), pp. 191-202.

${ }^{69}$ Ley N ${ }^{\circ} 20.416$ que fija normas especiales para las Empresas de Menor Tamaño, publicada en el Diario Oficial el 3 de febrero de 2010. Véase Historia de la Ley $N^{\circ} 20.416$, cit. (n. 59), pp. 524-526.

${ }^{70}$ Véase el "Segundo Informe Comisión de Economía del Senado", 16 de septiembre de 2009, en Historia de la Ley $N^{\circ} 20.416$, cit. (n. 59), pp. 360 ss. y 449 (dice que el Ministro de Economía incorporó la norma transcrita al proyecto de ley en cuestión a requerimiento de algunos senadores).

${ }^{71}$ Véase el "Oficio de Cámara de origen a Cámara Revisora, que aprueba las modi- 
de la República para proceder a los trámites necesarios para su entrada en vigencia $^{72}$. Pero la excepción en cuestión no habría de convertirse en ley.

Haciendo uso de sus facultades, la Presidente vetó la disposición en análisis. El veto se sustentaba en la infracción a compromisos internacionales en materia de derechos autorales, haciendo suponer que este tipo de limitaciones contrariaba el "Convenio de Berna" y el Acuerdo de la Organización Mundial de Comercio sobre los aspectos de los derechos de propiedad intelectual relacionados con el comercio ("Acuerdo de los ADPIC"), lo cual veremos es errado $^{73}$. En verdad, el veto tenía un sustento más político que jurídico, e intentaba evita un conflicto del Ejecutivo con el gremio de los artistas en un año electoral, a juzgar por su defensa a través del Ministerio General de la Presidencia y no por alguno de los restantes ministerios que representó al Ejecutivo durante la discusión legislativa. Con todo, el Congreso aún podía insistir en la adopción de la norma, pero para ello requería que la disposición del proyecto fuese ratificada por ambas cámaras ${ }^{74}$. Si bien el Senado rechazó el veto presidencial ${ }^{75}$, la Cámara de Diputados lo aceptó ${ }^{76}$. Como resultado de ello, la excepción a favor de pequeños y medianos establecimientos comerciales sucumbió.

La inclusión de una excepción específica para pequeños y medianos establecimientos comerciales a efectos de permitirles sintonizar radioemisoras y canales de televisión en sus dependencias no debería infringir los derechos de autores. Aunque la Constitución reconoce el derecho del autor sobre sus creaciones intelectuales y artísticas de cualquier especie ${ }^{77}$, también admite la imposición de limitaciones fundadas en la función social de la propiedad ${ }^{78}$. Por su parte, si bien los instrumentos internacionales en materia de derechos humanos reconocen derechos a los autores, también reconocen el derecho de terceros a tomar parte libremente en la vida cultural de la comunidad, a

ficaciones del Senado", 3 de noviembre de 2009, en Historia de la Ley $N^{o} 20.416$, cit. (n. 59), p. 639.

${ }^{72}$ Véase el "Oficio de Cámara de Origen al Ejecutivo: Oficio de Ley a S.E. la Presidenta de la República, comunicando el texto aprobado por el Congreso Nacional para efectos de ejercer la facultad de veto", 3 de noviembre de 2009, en Historia de la Ley $N^{o}$ 20.416, cit. (n. 59), pp. 640 et seq.

73 "Oficio del Ejecutivo a Cámara de origen, en que formula observaciones al proyecto de ley que fija normas especiales para empresas de menor tamaño", 9 de noviembre de 2009, en Historia de la Ley $N^{o} 20.416$, cit. (n. 59), pp. 674-675.

${ }^{74}$ Ley No 18.918 Orgánica Constitucional del Congreso Nacional, publicada en el Diario Oficial el 5 de febrero de 1990, artículos 32 a 36.

${ }^{75}$ Véase: Historia de la Ley $N^{o} 20.416$, cit. (n. 59), pp. 690-705.

${ }^{76}$ Ibíd., pp. 676-689.

${ }^{77}$ Artículo 19 No. 25 CPol.

${ }^{78}$ Artículo 19 No 25 en relación con artículo 19 № 24 incisos 2 a 5 CPol. 
gozar de las artes y a participar en el progreso científico y demás beneficios resultantes ${ }^{79}$. En cambio, la práctica de requerir un doble pago para difundir una transición radial o televisiva nos parece excesiva e injustificada, tal como la Corte Suprema ha tenido ocasión de expresarlo en diversos fallos en relación a la difusión de trailers de películas, y servicios de musicalización ambiental. En definitiva, tanto las normas constitucionales como las internacionales en materia de derechos humanos admiten el establecimiento de excepciones y limitaciones a los derechos de autor.

Los instrumentos internacionales en materia de derechos de autor facultan a los países para establecer excepciones y limitaciones a los derechos de autor, en tanto se respeten determinadas condiciones. Ya antes hemos mencionado la exigencia de adecuarse a la regla de los tres pasos prevista en el "Convenio de Berna" y el "Acuerdo sobre los ADPIC", conforme a los cuales las excepciones deben circunscribirse a determinados casos especiales, que no atenten contra la explotación normal de la obra, ni causen un perjuicio injustificado a los intereses legítimos del titular de los derechos. Este es el estándar que debe ser sopesado a la hora de definir el establecimiento de una excepción a favor de pequeños y medianos establecimientos comerciales, a efectos de permitirles difundir música en sus recintos mediante el uso de dispositivos receptores de radio y televisión.

Primero, de acuerdo a los instrumentos internacionales aplicables en materia de derechos de autor, las excepciones deben "circunscribirse a determinados casos especiales". Esto implica que la autorización debe cumplir un propósito específico y que no se admiten excepciones amplias que cubran una basta categorías de usos u obras ${ }^{80}$. Una excepción como la propuesta en este artículo cumple con esta exigencia, al fijarse diversas condiciones para que la autorización sea concedida: refiere sólo a aquellas obras que resultan perceptibles del simple hecho de sintonizar la radio o el televisión en determinada categorías de establecimientos, habilitando para la difusión de las mismas al interior de dichos establecimientos, no en las afueras ni a través de Internet.

Segundo, las excepciones no deben "atentar contra la explotación normal de la obra”. Esto supone dos análisis: primero, la modalidad de uso que es permitida por la limitación debe ser efectivamente susceptible de explotación autoral y, segundo, dicha explotación bebe ser permitida o deseada por la

${ }^{79}$ Véase, e.g.: Declaración Universal de los Derechos Humanos, adoptada y proclamada por la Resolución de la Asamblea General 217 A (III) del 10 de diciembre de 1948, artículo 27.

${ }^{80}$ UNCTAD-ICTSD, Resource Book on TRIPS and Development (Nueva York, Cambridge University Press, 2005), p. 190. 
ley $^{81}$. La excepción que proponemos intenta precisamente poner fin a una explotación no deseada por el legislativo, pero que, por un errado temor a infringir compromisos internacionales, ha rehuido encarar. El cobro de derechos autorales a pequeños y medianos establecimientos por simplemente mantener encendido un radio o televisión, en adición a aquellos derechos cobrados de la respectiva radioemisora o estación televisiva, es un pago injusto y doble. Incluso si el cobro es técnicamente posible (como de hecho sucede cotidianamente), él es jurídicamente reprochable. Dicho reproche obsta a que tal explotación pueda concebirse como la normal explotación de la obra.

Tercero, las excepciones no deben "causar un perjuicio injustificado a los intereses legitimos del titular de los derechos”. En otros términos, se admite que las excepciones pueden representar perjuicios a los derechos autorales, ya que en definitiva restringen el carácter monopólico de los mismos. Sin embargo, se impide que éstos perjuicios sean gravosos en términos injustificados $^{82}$. Precisamente, para evitar tal daño, la excepción que proponemos tiene varias cortapisas. Primero, sólo refiere a pequeñas y medianas empresas, excluyendo a aquellas de mayor tamaño. Segundo, la excepción no resultaría aplicable en el caso de establecimientos que obtienen beneficio económico directamente de la comunicación de obras musicales, por ser parte esencial de sus servicios. Extender la excepción más allá de dichos límites nos parece pueda incurrir en un perjuicio excesivo a los derechos de los creadores.

Una excepción a los derechos autorales que autorice, sin pago, a sintonizar y mantener encendido un radio o televisión dentro de las dependencias de pequeñas y medianas empresas, que no obtienen un beneficio económico directo de aquello, es consistente con las normas internacionales en materia de derechos de autor y, por consiguiente, no infringiría tales derechos. Esto aparece corroborado tanto experiencias de derecho comparado, como por alguna decisión de un panel de la Organización Mundial de Comercio sobre este punto en particular, según veremos.

En México, la ley prevé un nutrido número de excepciones y limitaciones a los derechos de autor ${ }^{83}$. Una de ellas permite el uso de obras en tiendas o establecimientos abiertos al público que comercialicen ejemplares de dichas obras, siempre y cuando no hayan cargos de admisión, la utilización tenga fines promocionales, y no exceda del recinto en cuestión ${ }^{84}$. Otra excepción

${ }^{81}$ UNCTAD-ICTSD, cit. (n. 79), p 192.

${ }^{82}$ Ibíd., p 193.

${ }^{83}$ Serrano, Fernando, Nueva Ley federal del derecho de autor (México, Porrúa, 1998), pp. 163-170 (analiza las limitaciones a los derechos patrimoniales de autor en la legislación mexicana).

${ }^{84}$ Ley federal del derecho de autor, publicada en el Diario Oficial de la Federación el 24 de diciembre de 1996 (texto actualizado al 27 de enero de 2012), artículo 149. 
permite a una empresa menor o una microindustria la comunicación de una transmisión recibida directamente en un aparato monorreceptor de radio o televisión del tipo comúnmente utilizado en domicilios privados, siempre que no medie cobro para ver u oír la transmisión o no forme parte de un conjunto de servicios, ni se retransmita la transmisión recibida con fines de lucro ${ }^{85}$. En otros términos, la ley permite a pequeños establecimientos mantener encendidos sus radiorreceptores y televisores para disfrute de sus dependientes y clientela, sin autorización ni pago, bajo determinadas circunstancias.

En Estados Unidos, la Copyright Act de 1976 codificó una excepción que permite a restaurantes, bares, oficinas, y otros establecimientos comerciales la recepción radial o televisiva a través de aparatos usualmente empleados en el hogar, siempre que no medie cobro para ver u oír la transmisión ${ }^{86}$. La excepción tiene su origen en la decisión previa de la Corte Suprema estadounidense que rechazó la demanda intentada contra el dueño de un pequeño local de comida rápida, quien había instalado un radiorreceptor y cuatro parlantes en su establecimiento para disfrute de sus dependientes y clientela. La Corte resolvió que el demandado era audiencia y no comunicador de las obras, y que "la extracción de múltiples pagos iria demasiado lejos para la protección de los titulares de derechos autorales" ${ }^{\prime \prime}$. En 1998, una nueva excepción con similares propósitos fue adicionada a la ley ${ }^{88}$. Inmediatamente, la Unión Europea inició un procedimiento contra los Estados Unidos ante la OMC, argumentando que ambas excepciones infringían la regla de los tres pasos del Convenio de Berna. La decisión del panel de la OMC acogió la alegación de la Unión Europea, pero sólo respecto de excepción incorporada en $1998^{89}$, no así la primera de ellas, que guarda analogía con la cual promovemos en este artículo. A la postre, Estados Unidos ha aceptado pagar indemnización a la Unión Europea ${ }^{90}$, y no ha modificado aún su legislación para adecuarse a la decisión mencionada.

En definitiva, las experiencias de México y Estados Unidos nos ofrecen

${ }^{85}$ Ibíd., artículo 150.

${ }^{86} \$ 110(5)$ (A) U.S. Copyright Act.

87 “Twentieth Century Music Corp. v. Aiken”, 422 U.S. 151 (1975). Véase GoRman, Robert - Ginsburg, Jane, Copyright: Cases and Materials (7 $7^{\mathrm{a}}$ edición, Nueva York, Foundation Press, 2006), pp. 700-703.

${ }^{88} \$ 110(5)$ (B) U.S. Copyright Act. Véase Cohen, Julie y otros, Copyright in a Global Information Economy (2a edición, Nueva York, ASPEN Publishers, 2006), pp. 470-472.

${ }^{89}$ Section 110(5) of the US Copyright Act, "Report of the Panel", June 15, 2000, (00-2284), WT/DS160/R.

${ }^{90}$ Véase: CHOw, Daniel - LEe, Edward, International Intellectual Property (St. Paul, Thomson/West, 2006), pp. 199-213. 
elementos suficientes para diseñar una excepción a favor de establecimientos comerciales que difunden música manteniendo encendido un aparato de radio o televisión. Primero, nos parece que la excepción debe quedar circunscrita a pequeños y medianos establecimientos, que son los que padecen costos más significativos por derechos y eventual litigación. Segundo, la comunicación a que refiere se concretiza sólo a través de los mencionados aparatos, no tiene lugar mediante la puesta a disposición en línea de contenidos. Tercero, el uso debe quedar circunscrito al recinto del establecimiento en cuestión. Cuarto, el establecimiento no puede cobrar ni obtener beneficio económico directo por la transmisión, lo cual importa excluir de entre sus beneficiarios a aquellos establecimientos en que la música constituye un elemento esencial de la prestación de servicios, tales como discotecas y bares.

Es difícil evaluar cuál sea exactamente el grado de afectación que el reconocimiento de una excepción como la propuesta pueda tener para los autores. A diferencia de las entidades de gestión de otros países, la SCD no ha estado acusada de la comisión de actos delictivos ni defraudatorios a los derechos de sus asociados, mas si ha sido calificada de poco transparente, inclusive por sus propios miembros. Existe escasa información pública respecto de la mencionada entidad de gestión colectiva de derecho ${ }^{91}$; sin embargo, disponemos al menos de las cifras oficiales del Instituto Nacional de Estadísticas ${ }^{92}$. De acuerdo a ellas, entre los años 2003 y 2010, la SCD distribuyó entre autores nacionales apenas un 11,9\% de su recaudación anual. El resto de los ingresos de la SCD se destinó a gastos administrativos, remesas a entidades de gestión colectiva en el extranjero, y pago a editores. Las remesas al extranjero superan el 34,6\%, siendo enviadas a terceros países, incluso si éstos, como en el caso de México y Estados Unidos, no envían a Chile monto alguno por concepto de difusión de obras de creadores chilenos en establecimientos comerciales, debido a la existencia de una excepción en su derecho interno a favor de ellos. En otros términos, aún siendo difícil evaluar sobre quién recae exactamente el peso de una excepción como la propuesta, las pocas cifras disponibles sugieren que ello no es sustantivamente sobre los hombros de los creadores nacionales.

${ }^{91}$ Lider de Illapu y Fernando Ubiergo Abren Polémica con SCD, en La Tercera, viernes 13 de julio de 2012, p. 60.

${ }^{92}$ Véase: Instituto Nacional de Estadística, Serie Estadística Anual Cultura y Tiempo Libre, disponible en http://www.ine.cl/canales/chile_estadistico/estadisticas_sociales_culturales/cultura/cultura.php [última visita: 16 de Julio de 2012]. 


\section{COMENTARIO FINAL}

El derecho de autor confiere a su titular un monopolio exclusivo para la explotación de sus obras. Nadie puede hacer uso de ellas, salvo autorización del propio titular o excepción prevista en la ley. De este modo, careciendo de una excepción específica a su respecto, los pequeños y medianos establecimientos comerciales que mantienen encendido su equipo radial o de televisión deben obtener autorización del titular y pagar el tarifado correspondiente. La jurisprudencia de los tribunales nacional, lamentablemente, no ha sido categórica en rechazar la exigencia de un doble pago de derechos autorales, considerando que tanto radioemisoras como canales de televisión ya han pagado para transmitir las obras a través de sus señales.

Para resolver tan injusto doble pago, durante la tramitación de la reciente reforma a la ley sobre derechos de autor y de la ley que fijó normas especiales para las empresas de menor tamaño, se discutió la inclusión de una excepción específica a favor de ciertos establecimientos comerciales, mas ninguna de ellas prosperó. El rechazo legislativo se sustentó, erradamente, en que una excepción de tales características infringiría las normas sobre derecho de autor previstas en instrumentos internacionales.

Este artículo arguye la necesidad de adoptar una excepción a favor de ciertos pequeños y medianos establecimientos, a efecto de permitir la difusión de obras musicales al interior de los mismos mediante la recepción de señal radial o televisiva, siempre que no se cobre ni lucre directamente por dicha transmisión. Como lo corroboran experiencias de derecho comparado e internacional, una excepción como la propuesta, adecuadamente diseñada, no infringe normas de derecho interno ni de derecho internacional y, en cambio, pone fin a un injusto doble pago.

\section{Bibliografía}

Alessandri, A. - Somarriva, M. - Vodanovic, A., Tratado de las obligaciones (2a edición, Santiago, Editorial Jurídica de Chile, 2001).

Álvarez, Daniel, En busca de equilibrios regulatorios: Chile y las recientes reformas al derecho de autor, en Documento de Politica, 12 (Ginebra, Centro para el Comercio y el Desarrollo Sostenible, 2011).

Barrientos, Javier, El pago de lo no debido en el Derecho chileno (Santiago, Lexis Nexis, 2003).

Biblioteca del Congreso Nacional de Chile, Historia de la Ley No 20.416 Que fija normas especiales para las empresas de menor tamaño (2010).

Biblioteca del Congreso Nacional de Chile, Historia de la Ley No 20.435 Modifica la Ley $N^{\circ}$ 17.336, sobre propiedad intelectual (2010). 
Cerda, Alberto - Ruiz, Claudio, Internet, Copyright y Derecho (Santiago, ONG Derechos Digitales, 2010).

Cerda, Alberto, Proyecto de ley corta sobre pirateria, modifica la Ley 17.336 sobre propiedad intelectual, en Revista Chilena de Derecho Informático, 4 (2004).

CHOw, Daniel - LeE, Edward, International Intellectual Property (St. Paul, Thomson/ West, 2006).

Cohen, Julie y otros, Copyright in a Global Information Economy (2a edición, Nueva York, ASPEN Publishers, 2006).

Ducci, Carlos, Derecho civil. Parte general (Santiago, Editorial Jurídica de Chile, 2007).

Gorman, Robert. Ginsburg, Jane, Copyright: Cases and Materials (7a edición, Nueva York, Foundation Press, 2006).

Herrera, Dina, Propiedad intelectual, derechos de autor: Ley $N^{\circ} 17.336$ y sus modificaciones (2a edición, Santiago, Editorial Jurídica de Chile, 1999).

Instituto Nacional de Estadística, Serie Estadistica Anual Cultura y Tiempo Libre (Santiago, INE, 2004-2010).

Muntañola, Mario Sol (moderador), Juan José Marín - José Carlos Erdozaín Agustín GonzÁlez, "Mesa Redonda: El test de las tres etapas y la comunicación pública", en Copyright y Derecho de Autor: ¿Convergencia Internacional en un Mundo Digital?, en Revista de Internet, Derecho y Politica de la Universitat Oberta de Catalunya, 1 (2005).

Oyarzún, Pablo (moderador), Oscar Acuña, Alberto Cerda, Nury González, y Santiago Schuster, "Mesa Redonda Resignificación del Patrimonio y Autoria", en VII Seminario Patrimonio Cultural: Territorios en conflicto ¿Por quéy para québacer memoria? (Santiago, DIBAM, 2005).

Puente Alba, Luz María, El ánimo de lucro y el perjuicio como elementos necesarios de los delitos contra la propiedad intelectual, en Revista Penal, 21 (2008).

RuIz, Claudio, Hacia una Dogmática para el Acceso en Chile, en CERDA, Alberto (editor), Acceso a la cultura y derechos de autor (Santiago, ONG Derechos Digitales, 2008).

Schuster, Santiago - Mahú, Jorge, Chile, en Hilty, Reto - Nérisson, Sylvie (editores), Balancing Copyright: A Survey of National Approaches (Heidelberg, Springer, 2012).

Serrano, Fernando, Nueva ley federal del derecho de autor (Ciudad de México, Porrúa, 1998).

UNCTAD-ICTSD, Resource Book on TRIPS and Development (Nueva York, Cambridge University Press, 2005). 